\title{
Sulfur Dioxide and Emergency Department Visits for Stroke and Seizure
}

\author{
Mieczysław Szyszkowicz, ${ }^{1}$ Eugeniusz Porada, ${ }^{1}$ Neil Tremblay, ${ }^{1}$ and Eric Grafstein ${ }^{2}$ \\ ${ }^{1}$ Population Studies Division, Health Canada, Ottawa, ON, Canada K1A OK9 \\ ${ }^{2}$ Department of Emergency Medicine, Providence Health Care and St. Paul's Hospital, Vancouver, BC, Canada V6Z 1 Y6
}

Correspondence should be addressed to Mieczysław Szyszkowicz, mietek.szyszkowicz@hc-sc.gc.ca

Received 10 December 2011; Revised 10 January 2012; Accepted 10 January 2012

Academic Editor: Halvor Naess

Copyright () 2012 Mieczysław Szyszkowicz et al. This is an open access article distributed under the Creative Commons Attribution License, which permits unrestricted use, distribution, and reproduction in any medium, provided the original work is properly cited.

\begin{abstract}
The purpose of this study was to assess an association between ambient sulfur dioxide and the number of emergency department (ED) visits for ischemic stroke and seizure. The study used data collected in a Vancouver (Canada) hospital in the years 19992003. Daily ED visits diagnosed as ministroke, stroke, or seizure were investigated using the case-crossover technique. Conditional logistic regression models were applied to estimate the odds ratios (ORs) and their respective 95\% confidence intervals (CIs). The models included temperature and relative humidity in the form of natural splines. The results were reported for an increase in interquartile range $\left((\mathrm{IQR}), \mathrm{IQR}=1.9 \mathrm{ppb}\right.$ for $\left.\mathrm{SO}_{2}\right)$. Positive and statistically significant associations were obtained for $\mathrm{SO}_{2}$ and ischemic stroke for all patients $(\mathrm{OR}=1.12$; CI 1.02, 1.23; lag 3$)$ and for female patients (OR = 1.17; CI 1.01, 1.33; lag 0). In the case of ED visits for seizure, for female patients the results were also statistically significant ( $\mathrm{OR}=1.15$; CI 1.02, 1.28; lag 1 and $\mathrm{OR}=1.18$; CI 1.05, 1.32; lag 2). These findings suggest that cases of ischemic cerebrovascular accidents are associated with acute exposure to ambient sulfur dioxide.
\end{abstract}

\section{Introduction}

The toxic, oxidative, and irritating properties of gaseous air pollutants are recognized health hazards $[1,2]$. Ambient sulfur dioxide $\left(\mathrm{SO}_{2}\right)$ is considered a risk factor for ischemic stroke and seizure, yet the mechanism of its effects on the brain is not currently readily understood. The gas when breathed in dissolves in the mucus lining of the upper respiratory tracts and thus affects their mechanical function, which may result in bronchoconstriction [3-5]. Connections between this syndrome and short-term exposure to $\mathrm{SO}_{2}$ have been reported [6]. Clinical assays suggested a synergism between this action of $\mathrm{SO}_{2}$ and a prior exposure to ozone [7]. But $\mathrm{SO}_{2}$ exposure arguably exacerbates the states of cardiopulmonary and cardiovascular diseases and increases the risk of premature death from circulatory system causes, including ischemic stroke [8-13]. The involvement of $\mathrm{SO}_{2}$ may be challenged on the basis that it tends to be correlated with toxic combustion particles [14], yet pathophysiologic images of animal stroke model after inhalation of $\mathrm{SO}_{2}$ show brain injuries similar to those caused by cerebral ischemia [15].
Understanding how exposure to $\mathrm{SO}_{2}$ causes the onset of brain ischemia would be helpful in preventing devastating health effects. Air pollution may affect the brain through multiple pathways, which are better understood in the case of photochemical pollutants causing neurodegeneration [2, $16]$, yet the pathway may include depression and symptoms of depression, which are risk factors for cerebral ischemia and stroke [17-24]. The ischemic injury caused by pollutants and the onset of stroke in patients affected by depression may involve the same pathophysiologic mechanism of action [25]. However, studies have found no associations between the presence of depressive symptoms and the risk of stroke in women, while $\mathrm{SO}_{2}$ associations are only found for women [26].

The present study contributes to the observations of the impact of four gaseous pollutants and two types of particulate matter on ED presentations of ischemic stroke and seizure. A seizure is often caused by conditions that reduce the supply of oxygen to brain cells, so this diagnosis is also included in the analysis [27]. This study mainly focused 
on sulfur dioxide exposure and ED visits for stroke or seizure. While the impact of the pollutants on the central nervous system is convoluted, a general pattern appears: sulfur dioxide contributes significantly to the occurrences or symptoms of cerebrovascular ischemia and seizure.

\section{Materials and Methods}

2.1. Study Population. The study population includes all patients serviced in the period from January 1999 to February 2003 by St. Paul's Hospital located in downtown Vancouver, BC. During that time the hospital was providing emergency health services for approximately 53,000 patients per year, with an admission rate of $15 \%$. A total of 194,443 visits with subsequent diagnoses were registered. The emergency physicians recorded the discharge diagnoses in ED charts using standardized medical vocabulary. The cases were identified using the corresponding standardized strings. The presentations of mini-stroke and stroke were recorded as transient ischemic attack $(n=307)$ and cerebrovascular accidentischemic $(n=695)$, respectively. These two diagnosed health conditions were combined and summarized to 1002 (females $=449$ ) cases. ED visits with the diagnosis of seizure were retrieved and totaled 2120 (females $=597)$ cases.

2.2. Meteorological Data. Environment Canada supplied hourly data for temperature, relative humidity, and atmospheric pressure for the city of Vancouver. We used the daily means of two weather parameters: temperature (dry bulb) and relative humidity. Each of these was calculated as an average of 24 hourly measurements.

2.3. Air Pollution Data. Hourly data for gaseous pollutants (concentrations of $\mathrm{CO}, \mathrm{NO}_{2}, \mathrm{SO}_{2}$, and $\mathrm{O}_{3}$ ) and particulate matter (PM, $\mathrm{PM}_{10}$, and $\mathrm{PM}_{2.5}$-PMs of less than 10 and $2.5 \mu \mathrm{m}$ in aerodynamic diameter, resp.) supplied by Environment Canada were obtained from a number of fixed continuous monitoring stations in the greater Vancouver area. During the study period ( 4 years and 2 months), the number of monitoring stations that reported air pollution data ranged from 4 to 11 . The distances of stations from the hospital varied from 3 to 43 kilometers. The measurements of the common daily exposure were obtained by first averaging the 24 hourly readings in each functioning station and next averaging across the stations.

2.4. Statistical Methods. Case-crossover methods are suitable for the estimation of odds of acute health effects triggered by acute and transient exposures [28]. The design is an adaptation of the case-control approach where the case serves as his/her own control. For each presented case of ischemia or seizure, the patient's exposure to pollutants on the case day (the day of admission or an earlier day when considering a lagged effect) was compared to the exposure on referent days when the patient has not been affected. The referent days were selected in a way to match year, month, and day of week of the case day, so that each case had 3 or 4 controls.
TABLE 1

\begin{tabular}{lccc}
\hline & Mean value & SD & IQR \\
\hline $\mathrm{CO}$ (in ppm) & 0.6 & 0.2 & 0.2 \\
$\mathrm{NO}_{2}$ (in ppb) & 16.8 & 4.6 & 6.2 \\
$\mathrm{SO}_{2}$ (in ppb) & 2.5 & 1.5 & 1.9 \\
$\mathrm{O}_{3}$ (in ppb) & 14.2 & 7.4 & 10.9 \\
\hline
\end{tabular}

TABLE 2

\begin{tabular}{lccc}
\hline & Mean value & SD & IQR \\
\hline $\mathrm{PM}_{10}\left(\right.$ in $\left.\mu \mathrm{m} / \mathrm{m}^{3}\right)$ & 25.8 & 14.2 & 6.9 \\
$\mathrm{PM}_{2.5}\left(\right.$ in $\left.\mu \mathrm{m} / \mathrm{m}^{3}\right)$ & 8.6 & 6.7 & 5.1 \\
\hline
\end{tabular}

Conditional logistic regression analysis was used to estimate the odds ratios (ORs) with 95\% confidence intervals (CIs) associated with an increase by conventional unit in the concentrations of pollutants. In order to compensate for possible nonlinear effects of the weather conditions (temperature, relative humidity), natural splines of the weather parameters, with 3 degrees of freedom, were incorporated into the regression models. Potential links between a pollutant and a health outcome were evaluated with singlepollutant models in order to assess the stability of the method and the causal nature of the association. The analysis was performed for all realistic combinations of the gaseous pollutants and PMs, individually lagged with different 0- to 7-day lags. The calculations were performed using the PHREG procedure in SAS.

In addition, we constructed the sequence of the age groups as follows: $(0,29),(1,30)$, and so on up to $(56,85)$. Thus, each age group spans 30 years. It was chosen arbitrarily and was driven by number of ED visits. For larger number of cases the groups may have shorter span. The first age group $(0,29)$ contains the patients not older than 30 years. The next $(1,30)$ has patients older than 1 year of age and younger than 31 , and so on. For each age group the calculations were performed separately for the health outcomes considered here, that is, stroke and seizure. This analysis was performed only for females and the same-day exposure (lag 0) to sulfur dioxide. The results were compared with similar calculations done for female ED visits for depression and anxiety.

\section{Results and Discussion}

The mean value of temperature during the study period was $7.7^{\circ} \mathrm{C}$, with a standard deviation (SD) of 11.4. Relative humidity had a mean value of $70.7 \%$, with $\mathrm{SD}=12.5$. These values reflect the generally tepid and humid weather in the city of Vancouver and its surroundings. For the gaseous pollutants, the point statistics are as shown in Table 1.

In the case of particulate matter, the corresponding statistics are as shown in Table 2.

The average pollution levels in Vancouver are comparable to those in other large urban regions in Canada, but Vancouver's ozone level is among the lowest in Canada [29, 30]. Mostly suburban areas had higher ozone levels and 


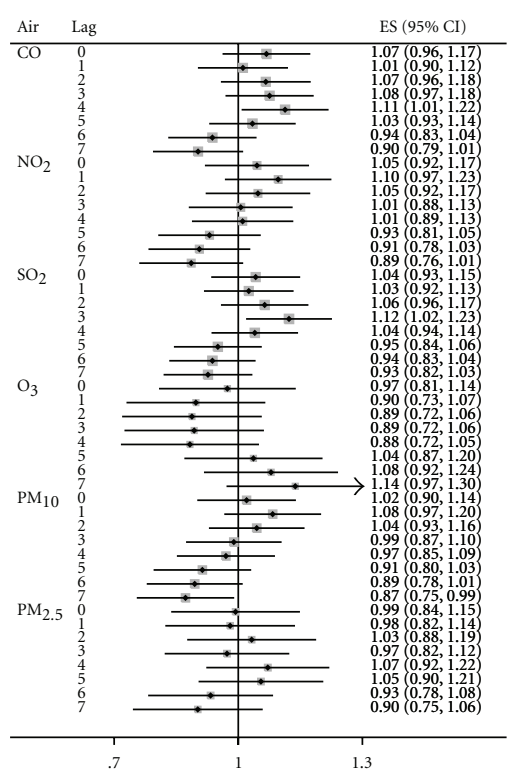

(a)

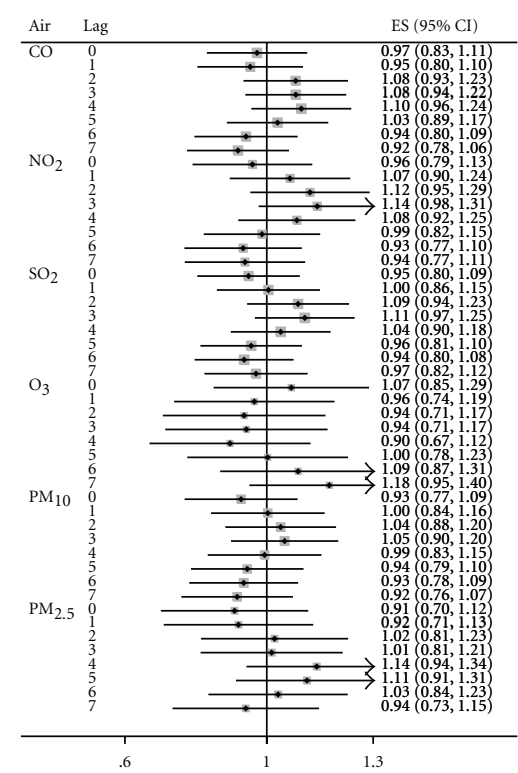

(b)

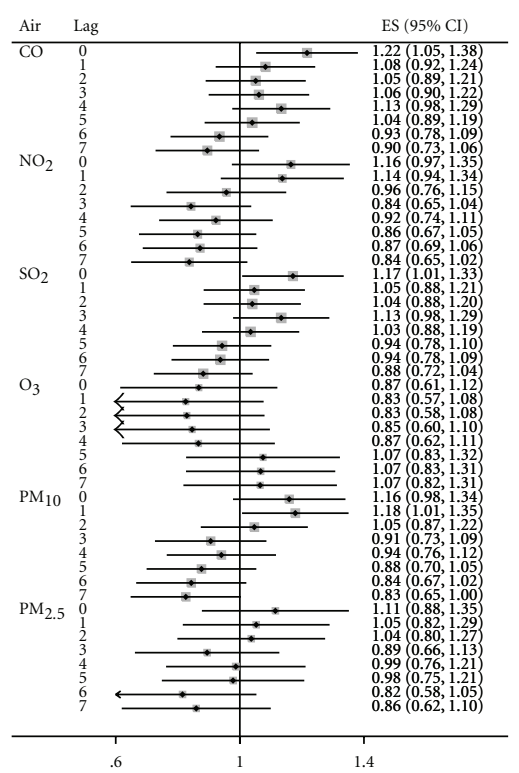

(c)

FIGURE 1: Odds ratios for ED visits for stroke associated with exposure to air pollutants.

were showing larger-range variation than that for downtown Vancouver, where the St. Paul's Hospital is located.

The results for ED visits for stroke are reported in Figure 1. The figure has three parts (in a horizontal direction) and shows the estimated ORs and their corresponding 95\% CIs for six considered air pollutants (lagged by 0 7 days) for all (a), male (b), and female (c) patients, respectively. The results are shown numerically and are also represented graphically as barlines. The results were positive and significant for all patients for exposure to $\mathrm{CO}$ (lag 4) and $\mathrm{SO}_{2}$ (lag 3), and none was significant in the case of male patients. For female patients the results were statistically significant $(P<0.05)$ for $\mathrm{CO}(\operatorname{lag} 0), \mathrm{PM}_{10}$ (lag 1$)$, and $\mathrm{SO}_{2}$ (lag 0 ). Table 3 presents the results from multipollutant models. In these models different combinations of lagged exposure were used. For example in the two-pollutant model $\mathrm{SO}_{2}$ (lag 3) $+\mathrm{O}_{3}$ (lag 6), early exposure to ozone (6 days before the event) increases effect of sulfur dioxide, and in this case OR $=1.16$ (95\% CI: $1.05,1.29)$. In this case weather parameters were used with lag 0 .

Figure 2 is constructed in a similar manner as Figure 1 and represents the results for ED visits for seizure. As in all cases, the results are reported for an increase in concentration of the air pollutant represented by its one IQR. The results ere positive and significant for all patients and for male patients and exposure to $\mathrm{PM}_{10}$ (lag 1, lag 4). For female patients, the association was significant for $\mathrm{SO}_{2}$ (lag 1 and 2) and ozone (lag 7).

Figure 3 represents the results for ED visits for stroke, seizure, depression, and anxiety for age groups of length 30 years. The results are shown for $\mathrm{SO}_{2}$ exposure on the same day as the health event. The pattern of responses (OR values and their respective $95 \%$ CIs) is very similar for seizure and depression. For anxiety, the pattern is weak but slightly similar for both mentioned health conditions [13].
Figure 4 illustrates levels of the gaseous air pollutants ( $\mathrm{CO}, \mathrm{NO}_{2}, \mathrm{SO}_{2}$, and $\mathrm{O}_{3}$ ) and daily number of $\mathrm{ED}$ visits for stroke (a) and for seizure (b). The figure indicates periodicity of carbon monoxide, nitrogen dioxide, and ozone. It also suggests that levels of ambient sulfur dioxide are decreasing.

The acute and often severe nature of symptoms of stroke and seizure results in the affected individuals first seeking help in the ED rather than in a doctor's office. This allows the frequency of ED visits for these disorders to be considered an adequate measure of the actual occurrences of the disorders in the examined population [31]. The presented results show that ambient sulfur dioxide constitutes a cerebrovascular health hazard, particularly for the female population. The findings in this study corroborate those in other studies on sulfur dioxide neurophysiologic effects [32]. They suggest that inhalation of $\mathrm{SO}_{2}$, rather than $\mathrm{O}_{3}$, may initiate a cerebral ischemic accident, causing specific pathophysiological effects on the brain. The mechanism has no analogy to the way bronchoconstriction occurs in vulnerable subjects exposed to $\mathrm{SO}_{2}$, where rather acidic compounds derived from $\mathrm{CO}$ and $\mathrm{SO}_{2}$ appear as agents of toxicity [33-38]. This suggests that $\mathrm{SO}_{2}$ may follow its own biochemical pathway of breaking through or penetrating the brain's protective barrier. The consequences appear to be stronger in the female population than in the male population. This calls for more clinical inquiry into the sulfur dioxide mediation mechanism in developing abnormal brain neural activity or brain ischemia.

The results of the current study should be considered in the context of its limitations. Regional estimates of exposure may not have correlated with patient-level exposures prior to visits to the $\mathrm{ED}$, which would bias the risk estimates towards the null. Possible correlation between health outcome severity and patient age and sex was not captured due to the limited number of observations. Some patients may have repeat visits to the emergency department for follow-up, and 


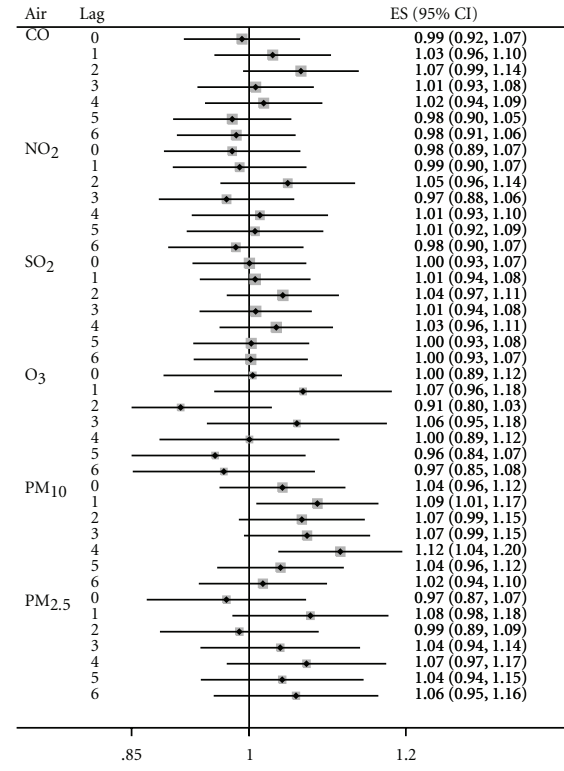

(a)

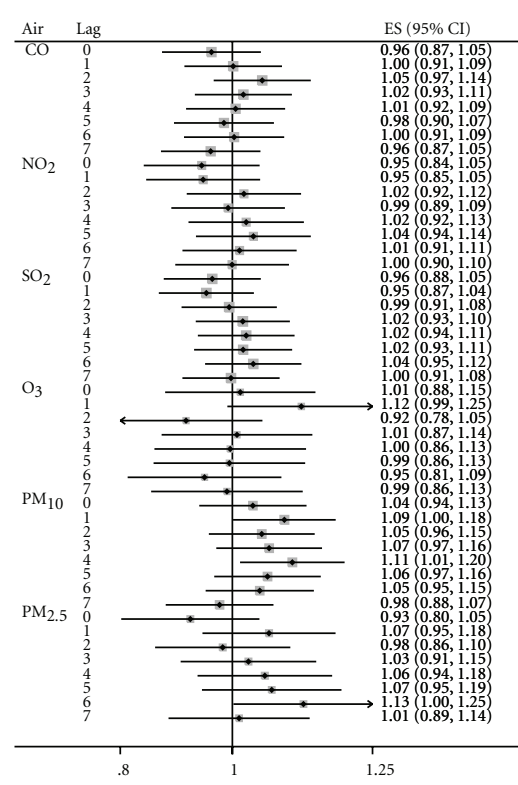

(b)

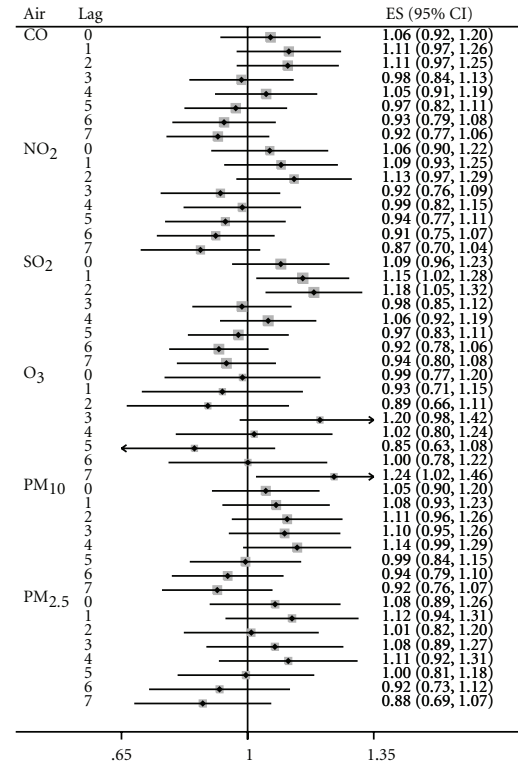

(c)

Figure 2: Odds ratios for ED visits for seizure associated with exposure to air pollutants.

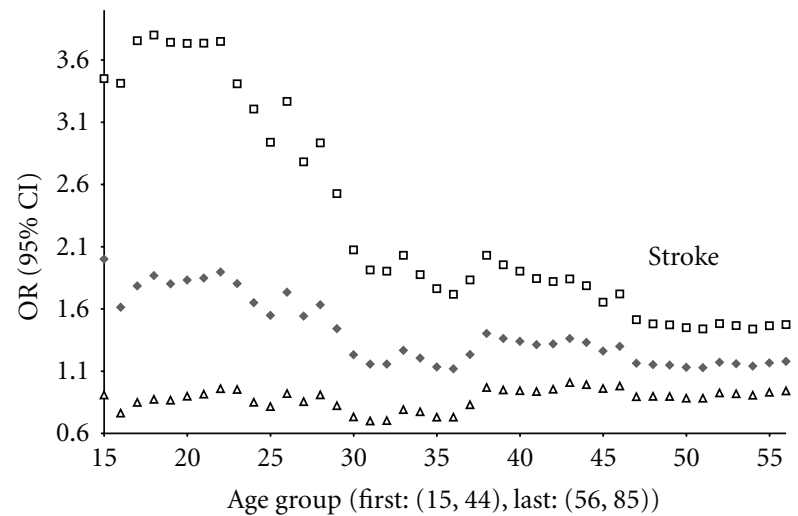

(a)

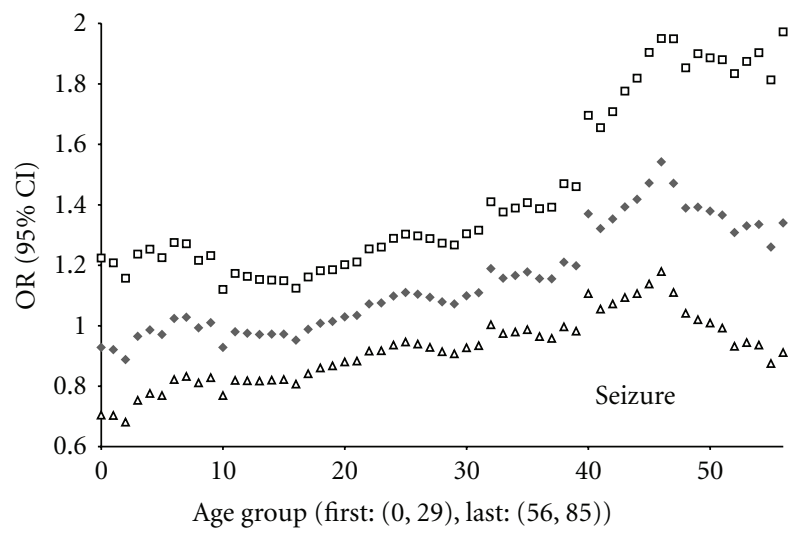

(c)

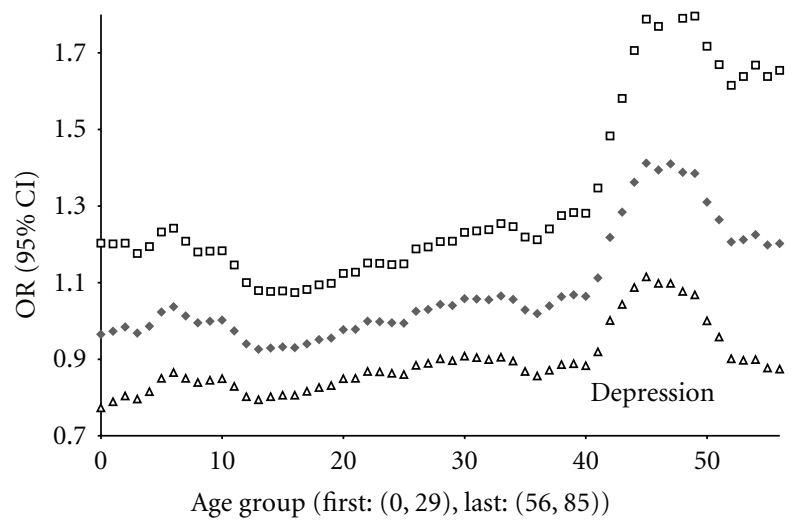

(b)

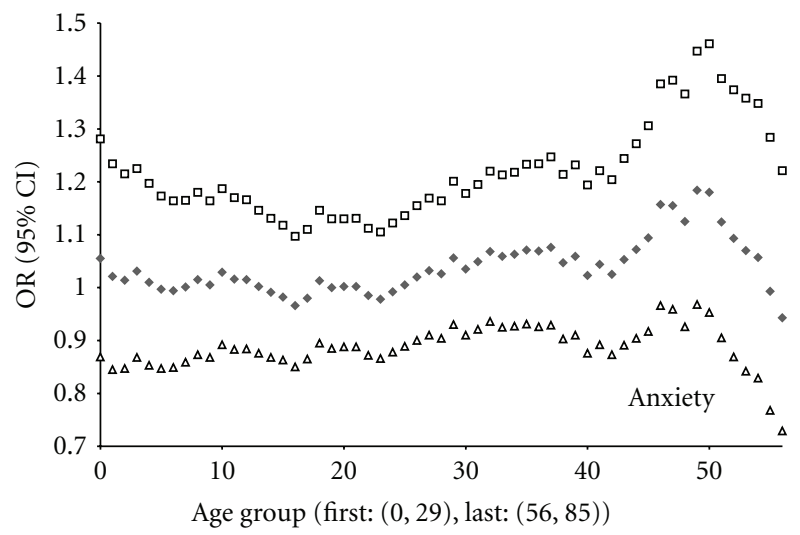

(d)

Figure 3: Odds ratios for female ED visits for stroke, seizure, depression and anxiety associated with exposure to $\mathrm{SO}_{2}$ - by age group. 
TABLE 3: Odds ratios and their 95\% confidence intervals for ED visits for ischemic stroke.

\begin{tabular}{|c|c|c|c|c|c|c|c|}
\hline \multirow{2}{*}{ Model } & \multicolumn{7}{|c|}{ Predictors } \\
\hline & & Lag & $\mathrm{SO}_{2}$ & Lag & $\mathrm{CO}$ & Lag & $\mathrm{O}_{3}$ \\
\hline \multirow{2}{*}{\multicolumn{2}{|c|}{$\mathrm{SO}_{2}$}} & 2 & $1.11(1.00,1.23)$ & & & & \\
\hline & & 3 & $1.15(1.04,1.27)^{*}$ & & & & \\
\hline \multirow{2}{*}{\multicolumn{2}{|c|}{$\mathrm{CO}$}} & & & 3 & $1.10(1.00,1.21)^{*}$ & & \\
\hline & & & & 4 & $1.12(1.02,1.23)^{*}$ & & \\
\hline \multirow{2}{*}{\multicolumn{2}{|c|}{$\mathrm{O}_{3}$}} & & & & & 5 & $1.02(0.89,1.18)$ \\
\hline & & & & & & 6 & $1.10(0.96,1.27)$ \\
\hline \multirow{2}{*}{\multicolumn{2}{|c|}{$\mathrm{SO}_{2}+\mathrm{O}_{3}$}} & 2 & $1.11(1.00,1.23)$ & & & 5 & $1.04(0.90,1.20)$ \\
\hline & & 3 & $1.16(1.05,1.29)^{*}$ & & & 6 & $1.13(0.98,1.30)$ \\
\hline \multirow{2}{*}{\multicolumn{2}{|c|}{$\mathrm{CO}+\mathrm{O}_{3}$}} & & & 3 & $1.12(1.01,1.23)^{*}$ & 5 & $1.07(0.92,1.24)$ \\
\hline & & & & 4 & $1.15(1.05,1.27)^{*}$ & 6 & $1.17(1.01,1.35)^{*}$ \\
\hline & \multirow{2}{*}{$\mathrm{SO}_{2}+\mathrm{CO}$} & 2 & $1.07(0.96,1.20)$ & 3 & $1.07(0.97,1.19)$ & & \\
\hline & & 3 & $1.11(1.00,1.24)^{*}$ & 4 & $1.07(0.97,1.19)$ & & \\
\hline & \multirow{2}{*}{$\mathrm{SO}_{2}+\mathrm{CO}+\mathrm{O}_{3}$} & 2 & $1.07(0.95,1.20)$ & 3 & $1.09(0.98,1.21)$ & 5 & $1.07(0.92,1.24)$ \\
\hline & & 3 & $1.11(1.00,1.24)^{*}$ & 4 & $1.11(1.00,1.24)^{*}$ & 6 & $1.17(1.01,1.35)^{*}$ \\
\hline
\end{tabular}

${ }^{*} P$ value $<0.05$.

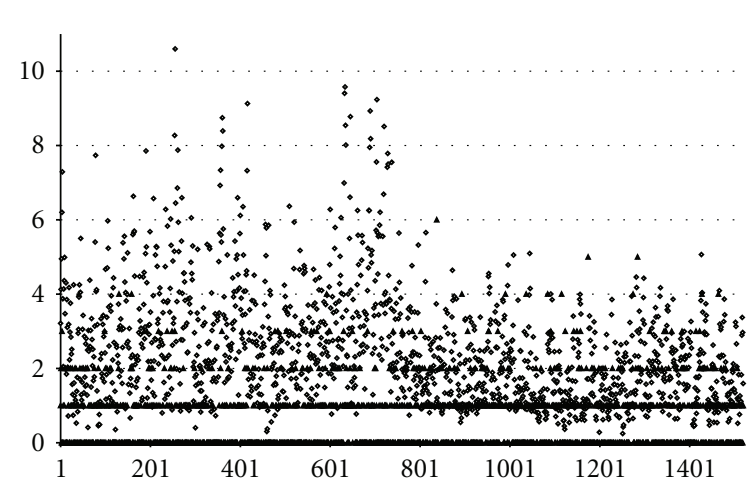

(a) Days (1520)

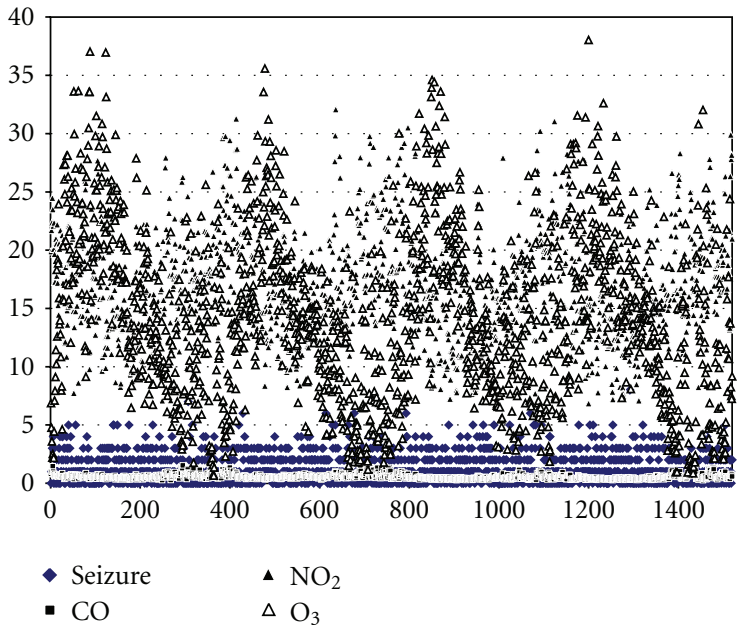

(b) Days (1520)

FIGURE 4: Air pollutants and daily counts of ED visits for stroke and seizure.

those visits would not be correlated to concentrations of air pollutants. While time-stable confounders (e.g., genetics and chronic diseases) are controlled for by the case-crossover study design, confounders that fluctuate in time may not have been controlled. Weather parameters (i.e., temperature and humidity) were adjusted in the analysis; however, measurements of acid aerosol concentrations were not available. Thus, future studies will be needed to replicate our findings and confirm that the increased risks of cerebral ischemia manifestations as stroke and seizures were due to the specific combinations of exposures.

This study suggests novel modifiable risk factors for ischemic stroke and seizure. Increases in concentrations of ambient sulfur dioxide were associated with increased probability of emergency department visit for ischemic cerebral accidents or transient ischemia. If these findings are confirmed, prevention of some cases of stroke or seizure may be achieved by improving air quality, or by better regulating the allowable levels of exposures to ambient gases in the workplaces.

\section{Acknowledgment}

The authors appreciate the efforts of Health Canada in securing these data and funding data acquisition.

\section{References}

[1] B. Brunekreef and S. T. Holgate, "Air pollution and health," The Lancet, vol. 360, no. 9341, pp. 1233-1242, 2002.

[2] M. L. Block and L. Calderón-Garcidueñas, "Air pollution: mechanisms of neuroinflammation and CNS disease," Trends in Neurosciences, vol. 32, no. 9, pp. 506-516, 2009. 
[3] D. Sheppard, W. S. Wong, and C. F. Uehara, "Lower threshold and greater bronchomotor responsiveness pf asthmatic subjects to sulfur dioxide," American Review of Respiratory Disease, vol. 122, no. 6, pp. 873-878, 1980.

[4] R. A. Bethel, J. Epstein, and D. Sheppard, "Sulfur dioxideinduced bronchoconstriction in freely breathing, exercising, asthmatic subjects," American Review of Respiratory Disease, vol. 128, no. 6, pp. 987-990, 1983.

[5] M. A. Bauer, M. J. Utell, and P. E. Morrow, "Inhalation of $0.30 \mathrm{ppm}$ nitrogen dioxide potentiates exercise-induced bronchospasm in asthmatics," American Review of Respiratory Disease, vol. 134, no. 6, pp. 1203-1208, 1986.

[6] C. Y. Yang and C. J. Chen, "Air pollution and hospital admissions for chronic obstructive pulmonary disease in a subtropical city: Taipei, Taiwan," Journal of Toxicology and Environmental Health A, vol. 70, no. 14, pp. 1214-1219, 2007.

[7] J. Q. Koenig, D. S. Covert, and W. E. Pierson, "Effects of inhalation of acidic compounds on pulmonary function in allergic adolescent subjects," Environmental Health Perspectives, vol. 79, pp. 173-178, 1989.

[8] J. T. Lee and J. Schwartz, "Reanalysis of the effects of air pollution on daily mortality in Seoul, Korea: a case-crossover design," Environmental Health Perspectives, vol. 107, no. 8, pp. 633-636, 1999.

[9] T. F. Mar, G. A. Norris, J. Q. Koenig, and T. V. Larson, "Associations between air pollution and mortality in Phoenix, 1995-1997," Environmental Health Perspectives, vol. 108, no. 4, pp. 347-353, 2000.

[10] Y. C. Hong, J. T. Lee, H. Kim, and H. J. Kwon, "Air pollution: a new risk factor in ischemic stroke mortality," Stroke, vol. 33, no. 9, pp. 2165-2169, 2002.

[11] S. S. Tsai, W. B. Goggins, H. F. Chiu, and C. Y. Yang, "Evidence for an association between air pollution and daily stroke admissions in kaohsiung, Taiwan," Stroke, vol. 34, no. 11, pp. 2612-2616, 2003.

[12] G. Chen, G. Song, L. Jiang et al., "Short-term effects of ambient gaseous pollutants and particulate matter on daily mortality in Shanghai, China," Journal of Occupational Health, vol. 50, no. 1, pp. 41-47, 2008.

[13] M. Szyszkowicz, "Ambient air pollution and daily emergency department visits for ischemic stroke in Edmonton, Canada," International Journal of Occupational Medicine and Environmental Health, vol. 21, no. 4, pp. 295-300, 2008.

[14] J. Schwartz, "Daily deaths are associated with combustion particles rather than $\mathrm{SO}_{2}$ in Philadelphia," Occupational and Environmental Medicine, vol. 57, no. 10, pp. 692-697, 2000.

[15] N. Sang, Y. Yun, H. Li, L. Hou, M. Han, and G. Li, " $\mathrm{SO}_{2}$ Inhalation contributes to the development and progression of ischemic stroke in the brain," Toxicological Sciences, vol. 114, no. 2, pp. 226-236, 2010.

[16] D. Gruol, T. Nelson, J. Sabeti et al., "CNS Actions of Inflammatory Factors,” The Scripps Research Institute: Molecular and Integrative Neurosciences, http://www.scripps.edu/ news/sr/sr2008/mind08gruol.html.

[17] K. J. Salaycik, M. Kelly-Hayes, A. Beiser et al., "Depressive symptoms and risk of stroke: the Framingham study," Stroke, vol. 38 , no. 1, pp. 16-21, 2007.

[18] P. G. Surtees, N. W. Wainwright, R. N. Luben, N. J. Wareham, S. A. Bingham, and K. T. Khaw, "Psychological distress, major depressive disorder, and risk of stroke," Neurology, vol. 70, no. 10, pp. 788-794, 2008.
[19] S. A. Everson, R. E. Roberts, D. E. Goldberg, and G. A. Kaplan, "Depressive symptoms and increased risk of stroke mortality over a 29-year period," Archives of Internal Medicine, vol. 158, no. 10, pp. 1133-1138, 1998.

[20] B. S. Jonas and M. E. Mussolino, "Symptoms of depression as a prospective risk factor for stroke," Psychosomatic Medicine, vol. 62, no. 4, pp. 463-471, 2000.

[21] S. L. Larson, P. L. Owens, D. Ford, and W. Eaton, "Depressive disorder, dysthymia, and risk of stroke: thirteen-year followup from the Baltimore Epidemiologic Catchment Area Study," Stroke, vol. 32, no. 9, pp. 1979-1983, 2001.

[22] T. Ohira, S. Satoh, T. Sankai et al., "Prospective study of depressive symptoms and risk of stroke among Japanese," Stroke, vol. 32, no. 4, pp. 903-907, 2001.

[23] L. A. Simons, J. McCallum, Y. Friedlander, and J. Simons, "Risk factors for ischemic stroke: dubbo study of the elderly," Stroke, vol. 29, no. 7, pp. 1341-1346, 1998.

[24] M. May, P. McCarron, S. Stansfeld et al., "Does psychological distress predict the risk of ischemic stroke and transient ischemic attack? The Caerphilly study," Stroke, vol. 33, no. 1, pp. 7-12, 2002.

[25] M. J. Bos, T. Lindén, P. J. Koudstaal et al., "Depressive symptoms and risk of stroke: the Rotterdam Study," Journal of Neurology, Neurosurgery and Psychiatry, vol. 79, no. 9, pp. 9971001, 2008.

[26] M. Szyszkowicz, B. Rowe, and I. Colman, "Air pollution and daily emergency department visits for depression," International Journal of Occupational Medicine and Environmental Health, vol. 22, no. 4, pp. 355-362, 2009.

[27] S. Cakmak, R. E. Dales, and C. B. Vidal, "Air pollution and hospitalization for epilepsy in Chile," Environment International, vol. 36, no. 6, pp. 501-505, 2010.

[28] H. Janes, L. Sheppard, and T. Lumley, "Case-crossover analyses of air pollution exposure data: referent selection strategies and their implications for bias," Epidemiology, vol. 16, no. 6, pp. 717-726, 2005.

[29] S. C. Pryor, I. G. McKendry, and D. G. Steyn, "Synoptic-scale meteorological variability and surface ozone concentrations in Vancouver, British Columbia," Journal of Applied Meteorology, vol. 34, no. 8, pp. 1824-1833, 1995.

[30] CCME (Canadian Council of Ministers of the Environment) Ground-level ozone and its precursors, 1980-1993, 1997.

[31] I. Mosley, M. Nicol, G. Donnan, I. Patrick, and H. Dewey, "Stroke symptoms and the decision to call for an ambulance," Stroke, vol. 38, no. 2, pp. 361-366, 2007.

[32] J. Joubert, T. B. Cumming, and A. J. McLean, "Diversity of risk factors for stroke: the putative roles and mechanisms of depression and air pollution," Journal of the Neurological Sciences, vol. 262, no. 1-2, pp. 71-76, 2007.

[33] R. W. Atkinson, H. R. Anderson, D. P. Strachan, J. M. Bland, S. A. Bremner, and A. Ponce De Leon, "Short-term associations between outdoor air pollution and visits to accident and emergency departments in London for respiratory complaints," European Respiratory Journal, vol. 13, no. 2, pp. 257-265, 1999.

[34] O. V. J. Rossi, V. L. Kinnula, J. Tienari, and E. Huhti, "Association of sever asthma attacks with weather, pollen, and air pollutants," Thorax, vol. 48, no. 3, pp. 244-248, 1993.

[35] G. D. Thurston, K. Ito, M. Lippmann, and C. Hayes, "Reexamination of London, England, mortality in relation to exposure to acidic aerosols during 1963-1972 winters," Environmental Health Perspectives, vol. 79, pp. 73-82, 1989.

[36] D. V. Bates and R. Sizto, "Air pollution and hospital admissions in Southern Ontario: the acid summer haze effect," Environmental Research, vol. 43, no. 2, pp. 317-331, 1987. 
[37] J. H. Ware, B. G. Ferris, and D. W. Dockery, "Effects of ambient sulfur oxides and suspended particles on respiratory health of preadolescent children," American Review of Respiratory Disease, vol. 133, no. 5, pp. 834-842, 1986.

[38] J. Sunyer, F. Ballester, A. Le Tertre et al., "The association of daily sulfur dioxide air pollution levels with hospital admissions for cardiovascular diseases in Europe (the Aphea-II study)," European Heart Journal, vol. 24, no. 8, pp. 752-760, 2003. 


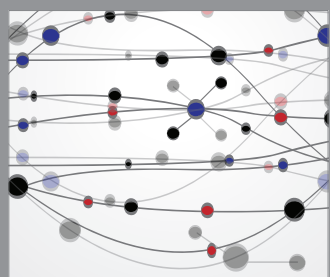

The Scientific World Journal
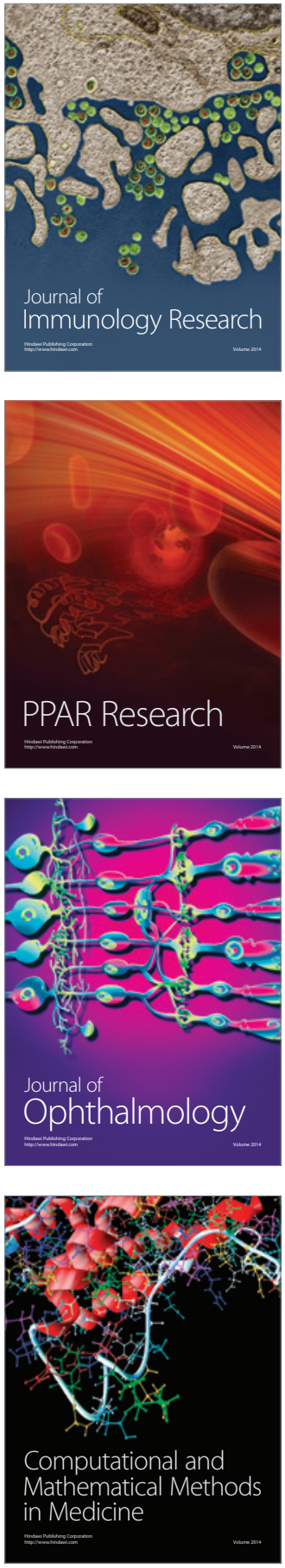

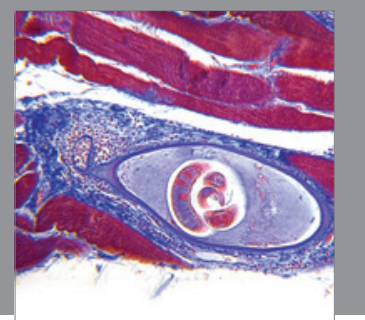

Gastroenterology

Research and Practice
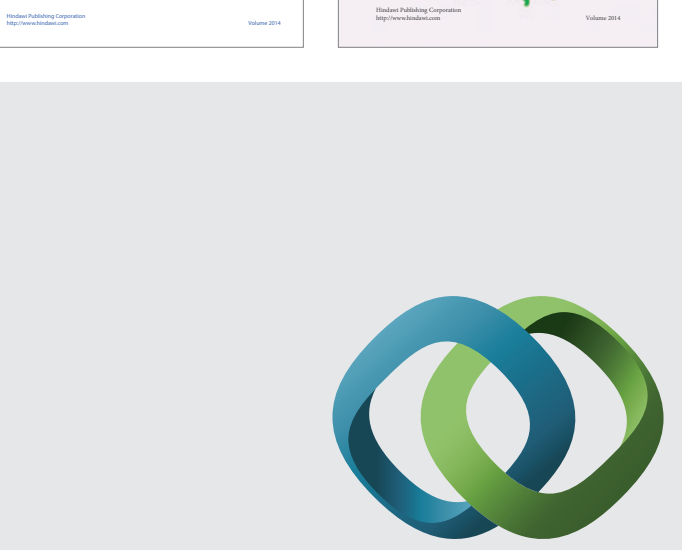

\section{Hindawi}

Submit your manuscripts at

http://www.hindawi.com
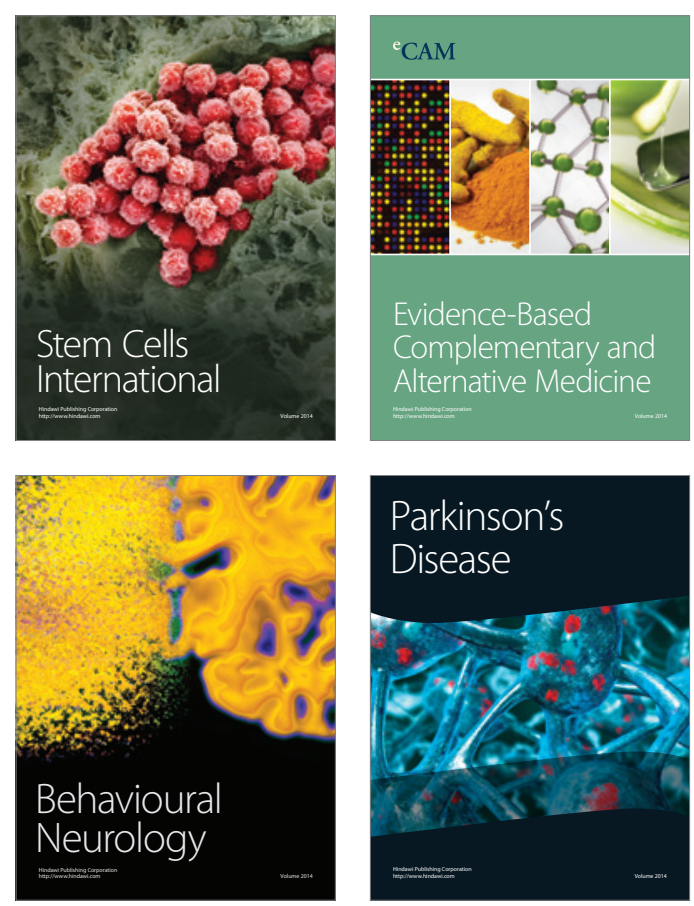

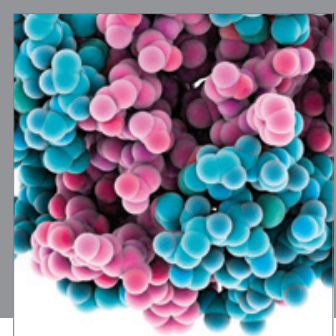

Journal of
Diabetes Research

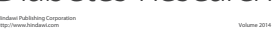

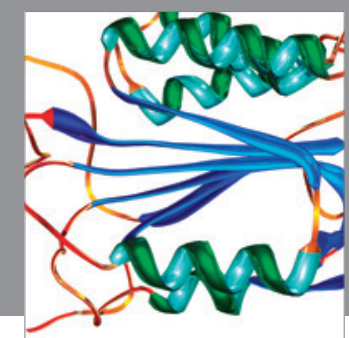

Disease Markers
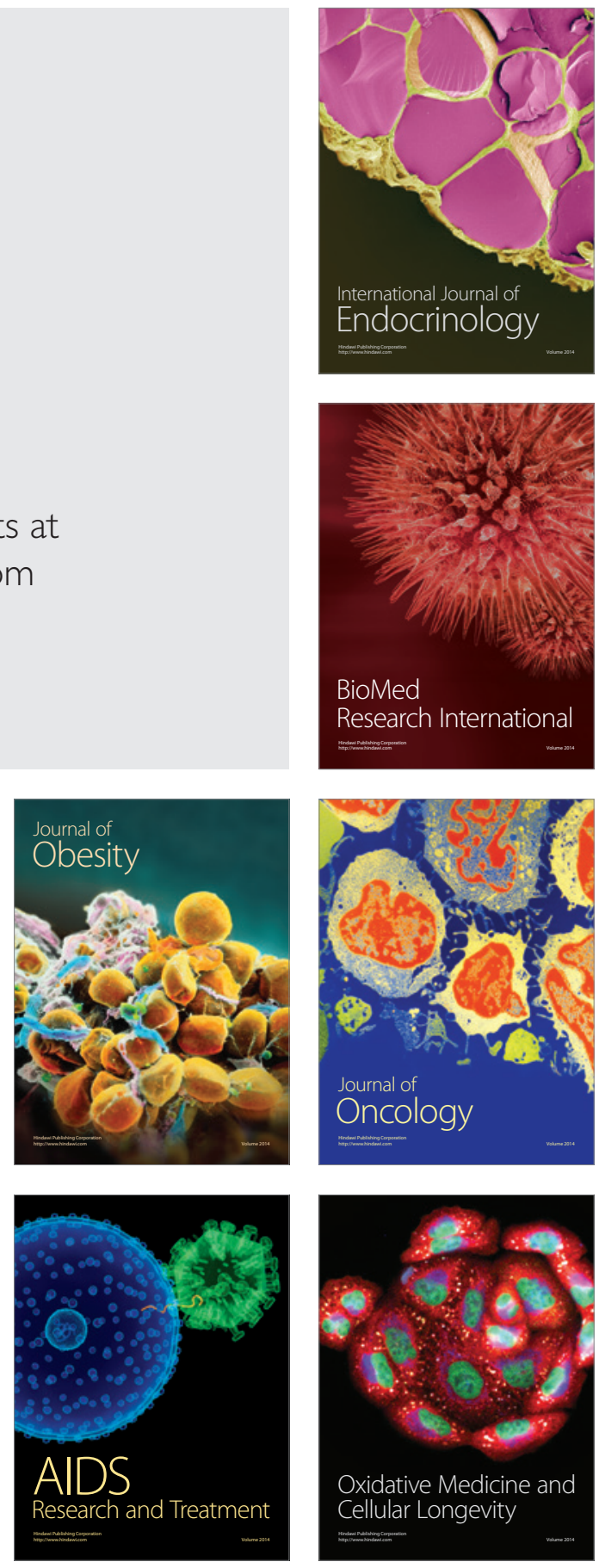